\title{
CHAPTER 15 \\ LONGSHORE CURRENTS IN ONE AND MULTI-BAR PROFILES RELATION TO LITTORAL DRIFT
}

\author{
Per Bruun \\ Head, Coastal Engineering Laboratory \\ University of Florida, Gainesville
}

\begin{abstract}
This paper deals with longshore current theories. Introductorily it gives a brief review of wave theories for breaking waves including theoretical, laboratory as well as field results. Next the longshore current theory based on the momentum inflow over a uniformly sloping beach and bottom (Putnam, Munk and Traylor, 1949) is discussed with special reference to its friction factor. The following chapters deal with two new longshore current theories - both based on the continuity principle. One of them called the rip current approach assumes that all water thrown in by wave breaking runs out in rip currents and will probably be valid for profiles with well developed bars and waves approaching the shore almost perpendicularly. The other theory considers the fact that water from a wave breaking under an angle with the bar flows in with a certain phase difference in time longshore and this will create a longshore slope of the average water table, therefore also a longshore current. The water may return to sea uniformly as undertow or in rip currents or by a combination of both. This theory is particularly valid for waves breaking under a certain, not too small, angle with the bar. In both cases the momentum in the breaking waves is ignored because field observations show that in a well developed bar profile most of the momentum has disappeared inside the bar after wave breaking.
\end{abstract}

Examples of computation of current velocities for one bar as well as multi-bar profiles are given. Next the possible relation between longshore currents and littoral drift is discussed.

\section{WAVE THEORIES AT WAVE BREAKING}

Before entering in any discussion on currents caused by wave breaking it is desirable briefly to review the application of existing wave theories to the shallow water area just outside and in the breaker zone.

The assumption underlying the linear Airy wave theory, namely that the wave height is small compared to the water depth, is not fulfilled in the area of the breaker zone. 


\section{COASTAL ENGINEERING}

Mathematical arguments show that stokes finite wave height theory is used when the depth to wave length ratio $\mathrm{d} / \mathrm{L}$ is greater than about $1 / 8$ to $1 / 10$ (Keulegan, 1950).

In this connection it should be noted that Bretschneider's (1961) recently developed theory for waves of finite height represents an exact theory to any order to which it is extended. An approximation by expansion of the exact equations is identical to Stokes' theory extended to the same order.

The theory of cnoidal waves (initiated in 1895 by Korteweg and de Vries) accounts for a general class of long waves of permanent type and finite amplitude; one limiting case of the theory gives the solitary wave, while another limiting case gives the sinusoidal wave as accounted for by linearized wave theory. Cnoidal wave theory as described by Wiegel (1960) is appropriate to periodic waves progressing in water whose depth is less than about one-tenth the wave length.

Laitone (1961) showed how the higher-order terms describing the vertical velocity variation, or the reversal of the pressure gradient, can predict a limiting height for cnoidal as we11 as solitary waves. The maximum amplitude is $8 / 11$ of the free water depth for the solitary wave. In addition it was found that the cnoidal waves are theoretically limited to the longer wave lengths corresponding to nearly critical, or supercritical speeds. It was also found that even for the higher approximations solitary waves can only occur at supercritical speeds.

When waves travel into water of depth less than a few times the wave height, wave crests narrow and become separated by long flat troughs. The character of these isolated crests scarcely depends upon the distance $L$ between the crests. Meanwhile, in Stokes' theory the wave length is contained in the two fundamental parameters: the depth/wave length and the height/length of the wave. Because of the apparent inadequateness of Stokes' theory, the solitary wave theory was suggested for application to surf problems (see e.g. Munk, 1949). Its advantages were soon confirmed by an obvious resemblance between the theoretically derived wave profile and the observed profile in the region just outside the breaker zone. The theory of the solitary wave, first developed by Boussinesq in 1871, was improved by McCowan in 1891, but received 1ittle attention, until Keulegan and Patterson published their theories (1940). 


\section{LONGSHORE CURRENTS IN ONE AND MULTI-BAR PROFILES RELATION TO LITTORAL DRIFT}

As described by Munk (1949), Boussinesq obtained a solution to the equations of motion for irrotational, nondivergent flow which is based on the expansion of the velocity potential in a power series.

$$
\phi=\sum_{n=0}^{\infty} \phi_{n} 3^{n}
$$

Retaining only the first two terms in the power series, Boussinesq obtained for the wave profile, $\mu=\sigma \operatorname{sech}^{2}(\sqrt{3 \gamma / 4} x)$ and for the wave celerity $C=\sqrt{g(h+\not t}=\sqrt{g h(1+r)}$ where $\mathrm{g}=$ acceleration of gravity, $\mathrm{h}=$ water depth, $\mathrm{H}=$ wave height, and $r=\mathrm{H} / \mathrm{h}$. The total volume of water per unit crest length above the still water level $Q$ is given by (see e.g. Le Mehaute, 1960).

$$
Q=4 h^{2} \sqrt{\frac{\pi}{3}}
$$

For the breaking wave, McCowan found the crest to be formed by two branches equally inclined to the bottom and cutting an angle of $120^{\circ}$. The corresponding ratio of wave height/water depth was 0.78 .

The energy flow at the breaking point is $\mathrm{Cb}_{\mathrm{b}} \frac{\mathrm{Eb}_{\mathrm{b}}}{\text { where }} \mathrm{E}_{\mathrm{b}} / \mathrm{L}_{\mathrm{b}}$ is the mean energy per unit surface area which by comparison with the energy flow in deep water gives: $H_{b}=H_{0} \cdot 3 \sqrt[3]{20} L_{0}$ where $\mathrm{H}_{\mathrm{b}}$ is breaker wave height and $\mathrm{H}_{\mathrm{O}}=$ deep water wave height.

The momentum flow at the breaking point is $\mathrm{C}_{\mathrm{b}} \cdot \mathrm{Q}_{\mathrm{b}}$ where $\mathrm{C}_{\mathrm{b}}$ is the wave celerity at breaking and $\mathrm{Q}_{b}$ the total volume of water per unit crest length above the still water level of the breaking wave.

Experiments on orbital velocities associated with wave action near the breaker zone carried out by the Scripps Institution of Oceanography from the Scripps pier at La Jolla, California as described by Inman and Nasu (1956) showed that the maximum horizontal orbital velocities as observed in general compare more favorably with velocities predicted from solitary wave equations than the equations of Airy and Stokes particularly when the ratio of the wave height to water depth is greater than about 0.4 (just outside the breaking point). In breaking theories the point of incipient breaking is where the maximum internal velocity at the crest is the same as the celerity of the wave form. The results of limiting amplitudeto-depth ratio obtained on this basis by various investigators are, according to Ippen and $\mathrm{Kulin}$ (1955): Boussinesq, 0.73; 


\section{COASTAL ENGINEERING}

McCowan, 0.78; Davies, 0.83; Packham, 1.03; and Gwyther, 0.83; (a11 for waves breaking perpendicular to the shoreline). Ippen and $\mathrm{Kulin}$ found by laboratory experiments that the amplitudeto-depth ratios at breaking are considerably higher than the theoretical McCowan value of 0.78 for solitary waves in water of constant depth. On a 2.3 per cent slope, which is comparable to many prototype conditions, the observed ratio was found to be constant at 1.2 for all initial waves. For the steeper slopes this ratio was found to be higher, and it increased sharply with decreasing wave height. Generally it could also be stated that all waves broke in water shallower than predicted by theory and the observed amplitude increase during shoaling was considerably smaller than the theoretical increase called for by constant energy consideration.

Iversen (1952) found, by laboratory experiments, that the beach slope has a marked effect in that, for a given wave train, the breaker is approximately 40 per cent higher on a 1:10 slope than on a 1:50 slope. In nature most bars on the open seacoast will have a comparatively gentle slope e.g. 1:30 on the front side and a rather steep slope e.g. 1:10 on the back side.

These findings refer to long-crested waves which have equal characteristics whether they occur in a wide basin or in a narrow channel.

Fuchs (1951) investigated the mechanics of the shortcrested oscillatory waves which have no continuous crest because the turbulence of the wind is random not only in the direction of propagation but also at right angles to it. This helps to explain the absence of long-crested waves in deep water; in shallow water energy flux takes place, accounting for a more evenly distributed wave height. Long-crested waves, therefore, peak up more rapidly than the short-crested waves in shallow water. Energy flow along the wave crest is therefore also largest for high (steep) waves in shallow water and will increase rapidly as the waves approach breaking.

\section{LONGSHORE CURRENTS OUTSIDE THE BREARING ZONE}

During the passage of a wave train over the offshore bottom, waves approaching the shoreline obliquely will turn by refraction. It is to be expected that this turning will cause a current along the wave crest. Meanwhile, wave characteristics change simultaneously and in the area $0.1<d / L_{0}$ 


\section{LONGSHORE CURRENTS IN ONE AND MULTI-BAR PROFILES RELATION TO LITTORAL DRIFT}

$<0.3$ ( $d=$ water depth, $L_{0}=$ wave length in deep water) the wave height will be smaller than the deep water wave height with the waves travelling perpendicular to shore and this will also be true with waves approaching shore obliquely with modifications due to refraction. By energy and mass transport considerations it may then be seen that the longshore current caused by the turning of waves by refraction must be very small and about zero apart from the area just before wave breaking when mass transport increases rapidly and the wave crest starts "sliding" a little sideways in down drift direction.

But longshore current of any magnitude first comes into existence when waves break causing water masses to move in one direction with great velocities.

\section{LONGSHORE CURRENT THEORY BASED ON MOMENTUM THEORY}

Using the solitary wave theory Putnam, Munk, and Traylor (1949) developed a longshore current theory based on momentum inflow under breaker angle with the shoreline of the water masses contained in the breaking wave (Figure 1 ) which is adequately described by the solitary wave theory. The momentum inflow's longshore component is $Q \cos \alpha_{b} \cdot C \sin \alpha_{b}$ $(Q=$ water mass per unit length of wave crest, $C=$ wave celerity (water velocity) at breaking, $\alpha_{b}=$ breaker angle). The loss of momentum by return flow of water to the area outside the breaker zone is $Q \cos \alpha_{b} \times V$, where $V$ is the longshore current velocity. Balancing bottom shear stresses against momentum gives the expression for $v$ :

$$
V^{2}=\frac{Q \cos \alpha_{b}}{a k T}\left(\cos \alpha_{b}-V\right)
$$

where $a$ is the distance between the breaking point of the waves and the shoreline, $T$ is the wave period, and $k$ is a friction parameter.

In above expression a uniformly sloping beach and offshore bottom are considered. Furthermore an immediate and direct return of water from the breaking waves to the offshore area is assumed. This may be correct for shores having steep bottom profiles and, therefore, little or no bar formation. With less steep shores and shores with one or more offshore bars the mechanism of the longshore current is different. Water masses thrown in by wave breaking do not return as a comparatively equally distributed "undertow" but will tend to flow a certain distance along the shore and 


\section{COASTAL ENGINEERING}

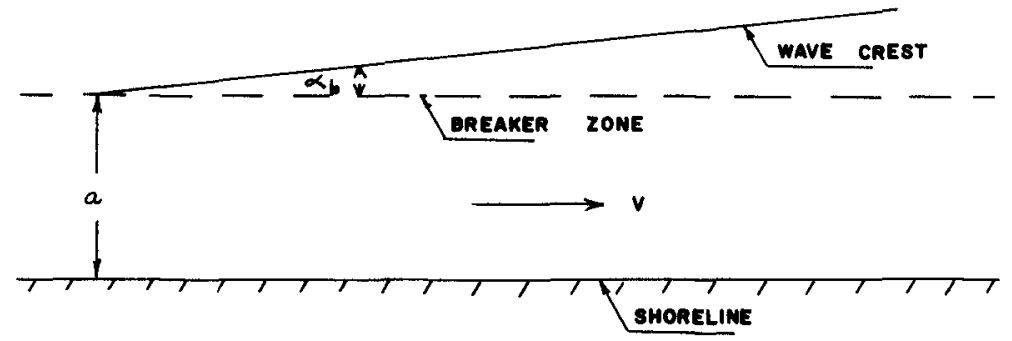

Fig. 1. Iomentum approach.
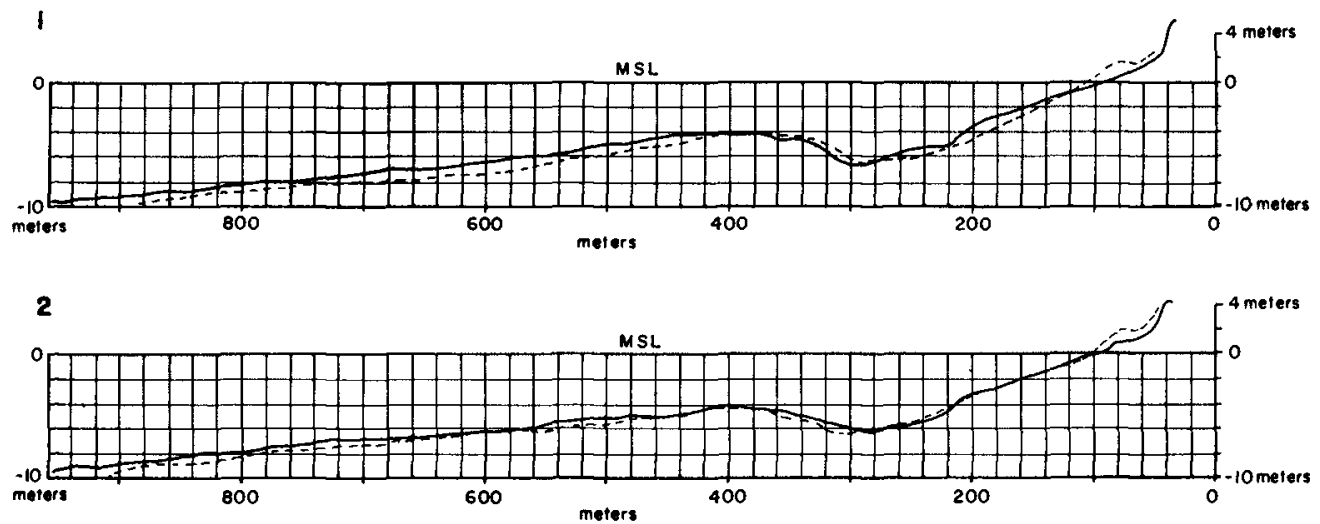

Fig. 2. Profiles at Bovojaerg, Danish North Sea Coast.

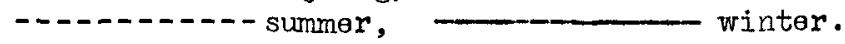




\section{LONGSHORE CURRENTS IN ONE AND MULTI-BAR PROFILES RELATION TO LI'T'TORAL DRIFT}

return in rip currents, which are currents running out perpendicularly to the shoreline. With respect to the $k$-value, it should be borne in mind that $k$ depends on the hydraulic roughness of the beach rather than on the absolute roughness of the beach surface. Certain laboratory and field data are available as described by Putnam, Munk, and Traylor, (1949) .

Inman and Quinn (1952) describe current experiments at Torrey Pines Beach, north of La Jolla in Southern California. Surface and bottom currents in the surf zone (inside the breaking point) were measured at 15 equally spaced points along two straight beaches having approximately parallel bottom contours. The results were subject to a statistical evaluation which demonstrated that the variability of the longshore current component as measured by its standard deviation is equal to or larger than the mean longshore velocity. It was found that the momentum approach by Putnam et al leads to useful forecasts, provided the friction coefficient $k$ is permitted to vary with the longshore velocity as indicated by the relation $k \sim v^{-3 / 2}$. For field data $k=0.020 \times v^{-1.51}$ (dimensionless); for laboratory data $k=0.029 \times \mathrm{V}^{-1.54}$. In this respect it is interesting to note a certain similarity to unidirectional flow where the friction coefficient decreases with increasing mean velocity when the transition area from ripples to dunes causing a heavy increase in friction has been passed. The transition from rippled to duned bottom occurs at mean velocities from about $0.3 \mathrm{~m} / \mathrm{sec}$ to $0.4 \mathrm{~m} / \mathrm{sec}$. Meanwhile this fact should not be misinterpreted because, as stated by Inman and Quinn (1952) the kvalues found for longshore currents refer to bottom material ranging from $\frac{1}{4}$ inch pea gravel through sand to smooth concrete; the type of bottom apparently is not as important as the velocity is for the value of $k$. In other words the hydrodynamic elements involved in $k$ may have the predominant influence on the actual $k$ value.

Table 1 gives field data for $k$ and $C_{f}$ for various velocities in feet as well as in the metric system.

TABLE 1. $k$ anc $C_{f}$ friction values

\begin{tabular}{lrrrrr}
\hline $\mathrm{V}$ ft $/ \mathrm{sec}$ & 1 & 2 & 3 & \multicolumn{1}{c}{4} & \multicolumn{1}{c}{5} \\
\hline $\mathrm{V} \mathrm{m} / \mathrm{sec}$ & 0.3 & 0.6 & 0.9 & 1.2 & 1.5 \\
\hline $\mathrm{k}$ & 0.020 & 0.0071 & 0.0038 & 0.0025 & 0.0018 \\
\hline $\mathrm{C}_{f} \mathrm{ft}^{\frac{1}{2}} / \mathrm{sec}$ & 40 & 67 & 91 & 112 & 134 \\
\hline $\mathrm{C}_{f} \mathrm{~m}^{\frac{1}{2}} / \mathrm{sec}$ & 22 & 39 & 50 & 62 & 74 \\
\hline
\end{tabular}




\section{COASTAL ENGINEERING}

For the velocity range 2 to about $4 \mathrm{ft}$. these values are comparable with those found by Bruun and Gerritsen (1960) for tidal inlets, although the flow conditions are different. Meanwhile, for troughs behind bars, it is probably better to use $C_{f}$ values derived from the experience formula $C_{f}=30+5 \log$ $A$, where $A$ is the cross-sectional trough area in $\mathrm{m}^{2}$ and $C_{f}$ is in $\mathrm{m}^{\frac{1}{2}} / \mathrm{sec}$. The corresponding value for $C_{f}$ in feet is $C_{f}=45+$ $\log A$ where $A$ is $\mathrm{ft}^{2}$ and $C_{f}^{\prime} s$ dimension is $\mathrm{ft}^{\frac{1}{2}} / \mathrm{sec}$. Values of $k$ for $V>5 \mathrm{ft} / \mathrm{sec}$ are very small and can hardly be compared to $C_{f}$ values from normal water courses. The velocities recorded by Inman and Quinn were of the order from $0.15 \mathrm{~m}$ ( $\frac{1}{2} \mathrm{ft}$ ) up to $1.25 \mathrm{~m}(4 \mathrm{ft})$ per sec. with a predominance around $0.75 \mathrm{~m}$ $(2.5 \mathrm{ft})$ per sec.

\section{LONGSHORE CURRENT THEORIES BASED ON THE CONTINUITY PRINCIPLE}

\section{GENERAL}

Handing of the current problem by means of the "continuity principle" seems beforehand to be a somewhat more realistic approach because while there is no doubt that the mass of water involved in wave breaking is preserved (apart from a little spray and foam) it is certain that considerable amount of momentum is lost by the wave breaking in eddy momentum, shocks and pressures, transfer of momentum by shear stresses to the bottom material and finally heat. Only a part of the momentum actually involved in a breaking is regenerated in momentum behind the breaking point whether this is in current or wave momentum.

Wave breaking in the prototype is influenced by a number of factors, including the depth, the wind field, and the longshore and rip currents.

The water particles in a wave just before breaking are moving with high velocities, e.g. 3 to 10 meters (10 to $30 \mathrm{ft}$ ) per second, and it is therefore difficult to define any particular breaking depth. In fact waves at breaking may pass over the crest of the bar so fast that they do not succeed in a breaking. The depth over the crest of the bar is not equal to the breaker depth for the breaking wave. It indicates the minimum cross section through which the water masses held in the breaking wave flow with a velocity which will normally be less than the water particle velocity at the breaking point, unless vaves break at the crest of the bar causing a maximum inflow of momentum at the minimum cross section. Inasmuch as no surveys of bottom topography can be made during stormy 


\section{LONGSHORE CURRENTS IN ONE AND MULTI-BAR PROFILES RELATION TO LITTORAL DRIFT}

weather it is not possible to give an exact figure for the actual breaker depth during storms, but it is increased by the tide (above normal) which usually occurs simultaneously and perhaps also by a minor figure indicating a certain erosion of the upper bottom layer during storms. It therefore depends upon local conditions, and tides and onshore winds will both increase the breaker depth. The laboratory ratio of 1.2 by Ippen and Kulin (1955), referring to experiments on solitary waves, can hardly be expected to be directly applicable in the prototype. Kressner (1928) states, on the basis of laboratory experiments, that waves will break on a slope when wave height equals water depth and that this is in agreement with field observations.

Technical Report Ho. 3 by the Beach Brosion Board (1948) describes a considerable number of bottom profiles obtained by long-term laboratory experiments and also gives some data on profiles from the German Baltic coast as well as from Lake Michigan. From these data it appears that the depth over the bar is 20 to 40 per cent smaller than the height of the breaking waye. This seems to be in agreement with Kressner's findings.

During calm weather periods between storms there will be certain movements of the bar as demonstrated by Figure 2 from the Danish North Sea Coast at Bovbjaerg. Full lines indicate winter (storm) and dotted lines summer (swe11) profiles. It will be seen that there is only a minor difference between the two profiles and inasmuch as most summer swells do not break over the bar it must mean that the (vertical) dimensions of the bar are mainly governed by the storm (winter) waves with the accompanying high velocities of the water masses flowing over the bar.

To arrive at the velocity of the longshore current, detailed knowledge on wave data is necessary and particularly it is important to know which wave in the statistical picture is responsible for the development of the bar and the corresponding trough. Inasmuch as the current in the trough integrates the effect of all incoming waves it is a reasonable assumption that the trough is related to a current which depends upon the characteristics of the highest breaking waves. With respect to the bar, sand is pushed up on the bar by shear stresses by the incoming waves but the crest itself is shaved off by the breaking waves and its dimensions are most 1ikely governed by the highest waves also. This means that the bar crest probably is located deeper than corresponding to the 


\section{COASTAL ENGINEERING}

height of the average wave. On the basis of present knowledge it is, as already mentioned, not possible to evaluate closely which wave height the crest will tend to follow, and rip currents and a possible return flow (undertow) over the crest may play a role.

From field observations it appears that probably a maximum of one-third of the (highest) waves make a complete breaking and that although breaking may start on the seaward slope of the bar it may actually take place on or close to the crest of the bar. Most waves seem to slip over the bar unbroken or without completing a breaking although their height is close to the depth on the crest of the bar. During the peak of the storm wave activity the number of breaking waves may be $50 \%$.

For the computations mentioned below it is assumed that waves with actual height of $H 1 / 3$ (the average of the highest one-third of all waves) and up determined the elevation of the bar crest. This situation may be said to correspond to the swell situation after the peak of the wave action during the storm has been passed. Such situation will last considerably longer than the peak period. The "H $1 / 3$ wave" is in the following named $\mathrm{H}(1 / 3)$ to distinguish it from the significant wave height $\mathrm{H} 1 / 3$.

Based on the above mentioned results from laboratory and field experiments the breaker depth $h_{b}$ is assumed to be equal to $\mathrm{H}_{\mathrm{b}}$ and $\mathrm{Dcr}$ (depth over crest of bar) $=0.8 \mathrm{Hb}(1 / 3)$. This assumption seems reasonable but remains to be checked more closely. To find the inflow of water from wave breaking and to relate that to known bar data, the actual breaking depth $h_{b}$ for individual waves must be put in relation to Dcr. Reflection, usually of the order 5 to 10 per cent, as it may be seen during storms must be taken into consideration too.

$$
\text { One has: } \mathrm{h}_{\mathrm{b}}=\mathrm{H}_{\mathrm{b}}(1 / 3), \mathrm{h}_{\mathrm{bp}}=\mathrm{H}_{\mathrm{bp}}=1.25 \mathrm{Dcr} \frac{\mathrm{H}_{\mathrm{bp}}}{\mathrm{H}_{\mathrm{b}}(1 / 3)}
$$

Assuming 10 per cent reflection of wave height the breaker depth $h_{b p}$ to be used for computation of $Q_{b p}$ (the volume of water per unit length of wave crest) is $0.9 \times 1.25 \times$ Dcr $\frac{\mathrm{H}_{\mathrm{b}}}{\mathrm{Hb}(1 / 3)}=1.12 \mathrm{Dcr} \frac{\mathrm{H}_{\mathrm{bp}}}{\mathrm{Hb}(1 / 3)}$.

Using the solitary wave theory on breaking waves (Munk, 1949) and considering $Q_{B}$ as the inflow over a time period corresponding to $\mathrm{H}(1 / 3)$ actual height one has: 


\section{LONGSHORE CURRENTS IN ONE AND MULTI-BAR PROFILES RELATION TO LITTORAL DRIFT}

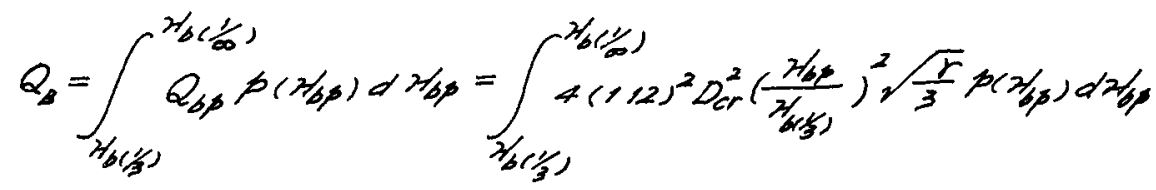
$r=\frac{\mathrm{Hbp}}{\mathrm{hbp}}$ is considered to be constant and equal to one. This will be almost true, and smaller deviations are unimportant because of the square root.

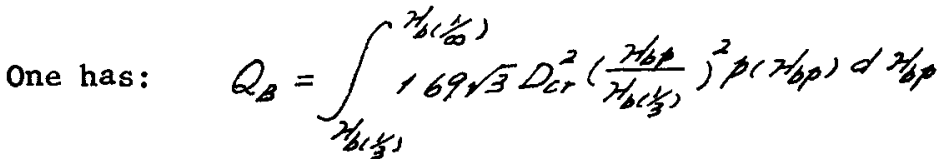

The statistical distribution of wave heights at breaking is so far little explored, but for the steep storm waves the distribution cannot be too different from the deep water spectrum. A comprehensive research program on this subject from towers placed in the ocean is being undertaken in Holland. For the computations below it is assumed that Longuet-Higgins' (1952) results for deep water waves are valid. With $p$ indicating probability density one has: $p(H) d H=e^{-\frac{H^{2}}{a^{2}}} \frac{2 H}{a^{2}}$ $d H$ or $\frac{P(H)}{a}=e^{-\frac{H^{2}}{a^{2}}} \frac{2 H}{a}$ where $p(H) d H=$ probability that any wave height $\mathrm{H}$ will occur between $\mathrm{H}$ and $\mathrm{H}+\mathrm{dH}$ and $\overline{\mathrm{a}}^{2}=$ $\frac{1}{N}\left(\mathrm{H}_{1}^{2}+\mathrm{H}_{2}^{2}+\cdots \cdot+\mathrm{H}_{\mathrm{N}}^{2}\right)$ or the mean of the squares of all occurring wave heights.

By taking

$$
\begin{aligned}
& \frac{H_{b}\left(\frac{5}{5}\right)}{\bar{a}}=1416 \text { or } H_{2(t)}=1146 \bar{a} \quad \text { then }
\end{aligned}
$$

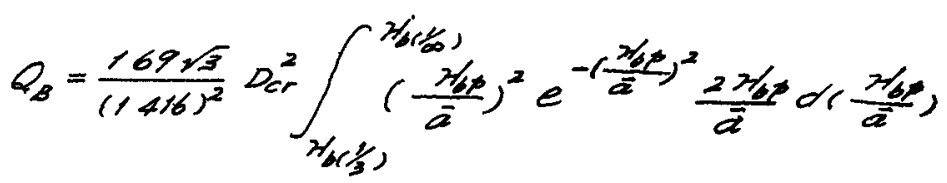




\section{COASTAL ENGINEERING}

Noting $\frac{N_{6}\left(\frac{3}{3}\right)}{\bar{a}}=1416, \frac{\pi / b\left(\frac{\pi}{a}\right)}{\bar{a}} \rightarrow \infty$ the expression of $Q_{B}$ is readily to be written into

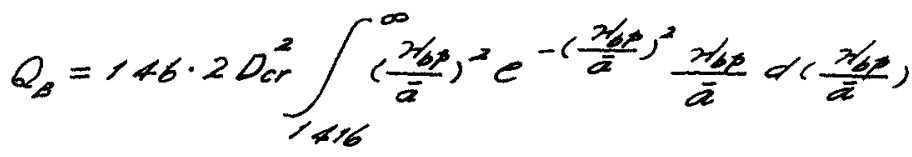

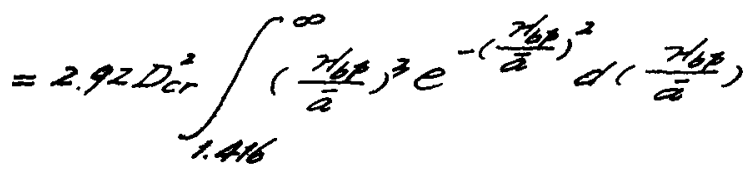

Let $\quad \frac{d b t}{a}=x \quad$ and change to numerical integration,

then

$$
Q_{B}=292 D_{c r}^{2} \sum_{1=160}^{\infty} x^{3} e^{-x^{2}} \Delta x
$$

Example: From Fig. 2

$$
D_{c r}=4.4 \mathrm{~m}, \quad D_{(b)}=1.25 D_{c r}=55 \mathrm{~m}, \quad \bar{a}=\frac{55}{1416}=389 \mathrm{~m}
$$

Taking $\Delta \frac{H_{\Delta t}}{\bar{a}}=\Delta \gamma=0.05$

then

$$
Q_{B}=292 D_{C r}^{2} \cdot 0.05 \sum_{1 \neq 16}^{\infty} x^{3} e^{-x^{2}}
$$

The numerical gives $Q_{B}=12.1 \mathrm{~m}^{3}$ per meter crest. The actual amount of water thrown in by the wave breaking is $12.1 \mathrm{~m}^{3} \cdot \cos \alpha_{b}$ per meter of the shore. 


\section{LONGSHORE CURRENTS IN ONE AND MULTI-BAR PROFILES RELATION TO LITTORAL DRIFT}

Comprehensive investigations by Hartnack (1926) on the coast of Pommern in the Baltic revealed the existence of up to six longshore bar systems although these systems were not continuous over a considerable length of shore. Along the Danish North Sea coast the number of bars increases in the direction of littoral drift from no bar at the very steep shore at Thyboroen located at the Lime Inlet to three to four bars at Skagen on the northernmost tip of Denmark, a distance of about 100 miles (Bruun, 1954). A similar phenomenon associated with decreasing steepness of the offshore bottom profile occurs when moving 70 miles south on the North Sea coast towards Blaavands Huk.

Each trough between the single bar systems carries its own longshore current and each bar system probably develops its own rip currents although because of the inertia included in a rip current it seems likely that one particular rip current may shoot directly through more than one (row of) bar(s), an assumption which seem to be confirmed to some extent by field observations.

When a wave breaks the water masses which it holds have a longshore velocity beforehand which may contribute to the longshore velocity inside the bar but the water included in the wave-breaking is derived from an area which does not carry strong longshore currents. When the water runs out again in a rip current longshore momentum is lost from the trough inside the bar and probably little longshore momentum is gained by the area or trough outside the bar because the rip current is nearly perpendicular to the shoreline. It receives water from both sides of the trough at its root.

\section{APPROACH BASED ON REGULARLY SPACED RIP CURRENTS}

Assumption for the approach described below, is that bars in a bar profile were built up by wave action with wave height characteristics as indicated by the water depth over the bars. It must be assumed that the individual parts of the bottom profile including bars, troughs, and the corresponding slopes, are in some kind of mutual interior balance with each other and with the wave and current forces which shaped them. Inasmuch as the depth surveys of such profiles are carried out not during, but after the storm it is not permissible uncritically to identify the calm weather (swell) profile with the stormy weather (steep-wave) profile. Certain adjustments of the storm profile took place at the end and after the storm. We do not know much about the quantitative extent of 


\section{COASTAL ENGINEERING}

these changes, but the qualitative trend undoubtedly goes in the direction of less depth over the bar during swell periods (Figure 2). The bar itself also moves a little closer to shore, thereby tending to decrease the cross-sectional area of the trough. A long calm-weather period may materially influence the configuration of the trough close to shore but may have comparatively little influence on troughs (and bars) farther offshore. The Coastal Engineering Laboratory of the University of Florida has initiated a field research program on this topic combined with littoral drift tracing with luminescent material.

Consider now a shore length of e.g. 1000 to $2000 \mathrm{ft}$., having transport of water perpendicular to the shore in the breaking zone and longshore transport of water in the trough between bar and shoreline. It is known that the longshore trough currents are irregular in velocity and in direction and it is observed that they flow toward the root of the rip current from both sides. Even if the general direction of the longshore current is indicated by the direction of wave approach and the breaker angle there is a local reversal of flow at every root of a rip current.

Rip currents occur at intervals determined by wave and offshore bottom characteristics. Larras (1957) lists 500 meters as an average space. They can usually be seen from the beach and are easily recognized from an airplane. They occur together with a lowering in the bar profile which moves slowly in downdrift direction (or it may jump a greater distance during storm periods). The flow characteristics (velocity and distribution of $f(0 w)$ in the longshore trough will gradually vary. Maximum cross-sectional area of the trough corresponds to maximum flow, but minor flow quantities do not necessarily cause the cross-sectional area (immediately) to adjust itself accordingly. This takes time. At the root of the rip current the shoreline will usually conform with the local flow conditions, and it may develop an S-shape or slight tombolo-1ike formation caused by the rip currents opposing the wave action. This may increase the loss of energy by wave breaking and change the wave characteristics, causing less erosive action.

In the theory mentioned below it is assumed that water derived from the breaking waves over a certain length parallel to shore flows out where hydraulically speaking it is easiest and because the inflow over the bar has caused a buildup of 


\section{LONGSHORE CURRENTS IN ONE AND MULTI-BAR PROFILES RELATION TO LITTORAL DRIFT}

head-difference between the (average) water table on the seaward and the shoreward side of the bar. It can still be discussed whether the more or less regularly spaced lowerings in the offshore bar system are caused by rip currents or whether the currents seek these incidental openings for discharge but this problem does not affect the theory discussed below. Also it must be assumed that part of the water may flow back over the bar outside the lowerings in a magnitude, depending upon how well the bar and trough are developed.

\section{With reference to Figure 3 :}

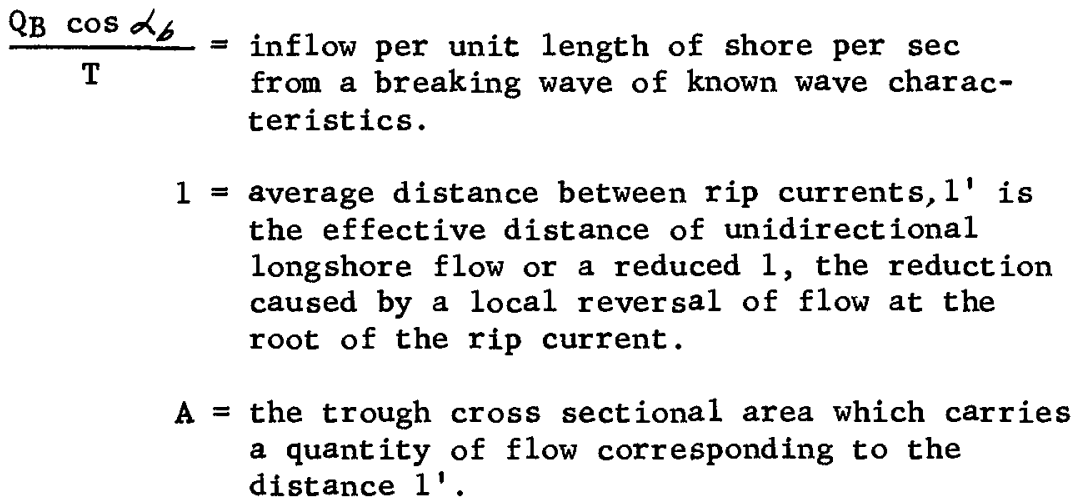

The general expression for current velocity $V_{x}$ at distance $x$ from the point where the longshore current velocity is zero is:

$$
v_{x}=\frac{Q_{B x} \cos \alpha_{b} \cdot x}{A_{X} \cdot T}
$$

With $\mathrm{x}=0, \mathrm{~V}_{\mathrm{X}}=0$ and $\mathrm{A}_{\mathrm{x}}$ could in fact be zero too inasmuch as it does not carry any flow. Figure 4 is an aerial photo from the south shore of Long Island at East Hampton and shows a $r i p$ current and a bar/trough system where $x$ and $A_{x}$ seems to have such "ideal" linear relationship. This will normally not be the case and longshore current velocity will increase from $x=0$ until $x=1^{\prime}$ and attain a maximum velocity:

$$
V=\frac{Q_{B} \cos \alpha_{b} 1^{\prime}}{A T}
$$

In this expression only the preservation of water mass is considered. Writing $V_{m}=C_{f} \sqrt{z_{s} / \rho g}$ where $V_{m}=$ the mean velocity of trough current, $C_{f}=$ Chezy's friction coefficient, 


\section{COASTAL ENGINEERING}

$\tau_{s}=$ "the determining shear stress for bottom stability" (Bruun and Gerritsen, 1960), $g$ = the acceleration of gravity and $\rho=$ the density of water, one has:

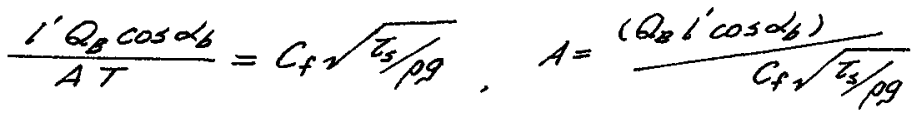

Table 2 has $\tau_{s}$ and the corresponding v-values, computed on the basis of Figure 2:s average values of $A\left(1030 \mathrm{~m}^{2}\right)$ and with breaker angle $\alpha_{b}=25$ degrees which with steep waves occurs with $\alpha_{0}=$ about $45^{\circ}$ to $50^{\circ}, \mathrm{T}(1 / 3)=8$ and $10 \mathrm{sec}$ a11 in agreement with observations and $\mathrm{c}_{f}$ values are 35 and 45 (metric) in accordance with results from tidal inlets. The above mentioned formula $\mathrm{C}_{f}=30+5 \log \mathrm{A}$ gives $\mathrm{C}_{\mathrm{f}}=45$ $\mathrm{m}^{\frac{1}{2}} / \mathrm{sec}$. Currents are computed for values of $1^{\prime}$ of 300 to 600 meters from actual observations and the $\mathrm{Q}_{\mathrm{B}}$ value is based on breaking waves from probability $\mathrm{p}=0.135$ to $\mathrm{p}=1 / \infty$ corresponding to Figure 2 as mentioned in paragraph 3 when a $Q_{B}$ value of $12.1 \mathrm{~m}^{3}$ per meter of the breaking wave crest was found.

Table 2. Continuity Rip Current Approach for Prototype Characteristics Corresponding to Figure 2.

\begin{tabular}{|c|c|c|c|c|c|c|c|}
\hline$\underset{\alpha_{b}}{\text { degrees }}$ & $\begin{array}{c}\mathrm{L}_{\mathbf{b}} \\
\text { meters }\end{array}$ & $\begin{array}{c}\mathrm{T}(1 / 3) \\
\text { sec } \\
\text { ave. }\end{array}$ & $\begin{array}{l}\mathrm{H}_{b}(1 / 3) \\
\text { meters }\end{array}$ & $\begin{array}{c}1^{\prime} \\
\text { meters }\end{array}$ & $\begin{array}{c}\tau s \\
\left(C_{f}=35\right. \\
\left.\mathrm{m}^{\frac{1}{2}} / \mathrm{sec}\right) \\
\mathrm{kg} / \mathrm{m}^{2}\end{array}$ & $\begin{array}{c}T S \\
\left(C_{f}=45\right. \\
\left.\mathrm{m}^{\frac{1}{2}} / \mathrm{sec}^{2}\right) \\
\mathrm{kg} / \mathrm{m}^{2}\end{array}$ & $\underset{\text { meter/sec }}{V_{\mathrm{m}}}$ \\
\hline \multirow[t]{4}{*}{25} & 55.0 & 8 & 5.5 & 300 & 0.130 & 0.078 & 0.40 \\
\hline & & & & 400 & 0.230 & 0.140 & 0.53 \\
\hline & & & & 500 & 0.360 & 0.218 & 0.67 \\
\hline & & & & 600 & 0.518 & 0.314 & 0.80 \\
\hline \multirow[t]{4}{*}{25} & 72.0 & 10 & 5.5 & 300 & 0.083 & 0.050 & 0.32 \\
\hline & & & & 400 & 0.148 & 0.089 & 0.43 \\
\hline & & & & 500 & 0.230 & 0.139 & 0.53 \\
\hline & & & & 600 & 0.332 & 0.201 & 0.64 \\
\hline
\end{tabular}


LONGSHORE CURRENTS IN ONE AND MULTI-BAR PROFILES RELATION TO LITTORAL DRIFT
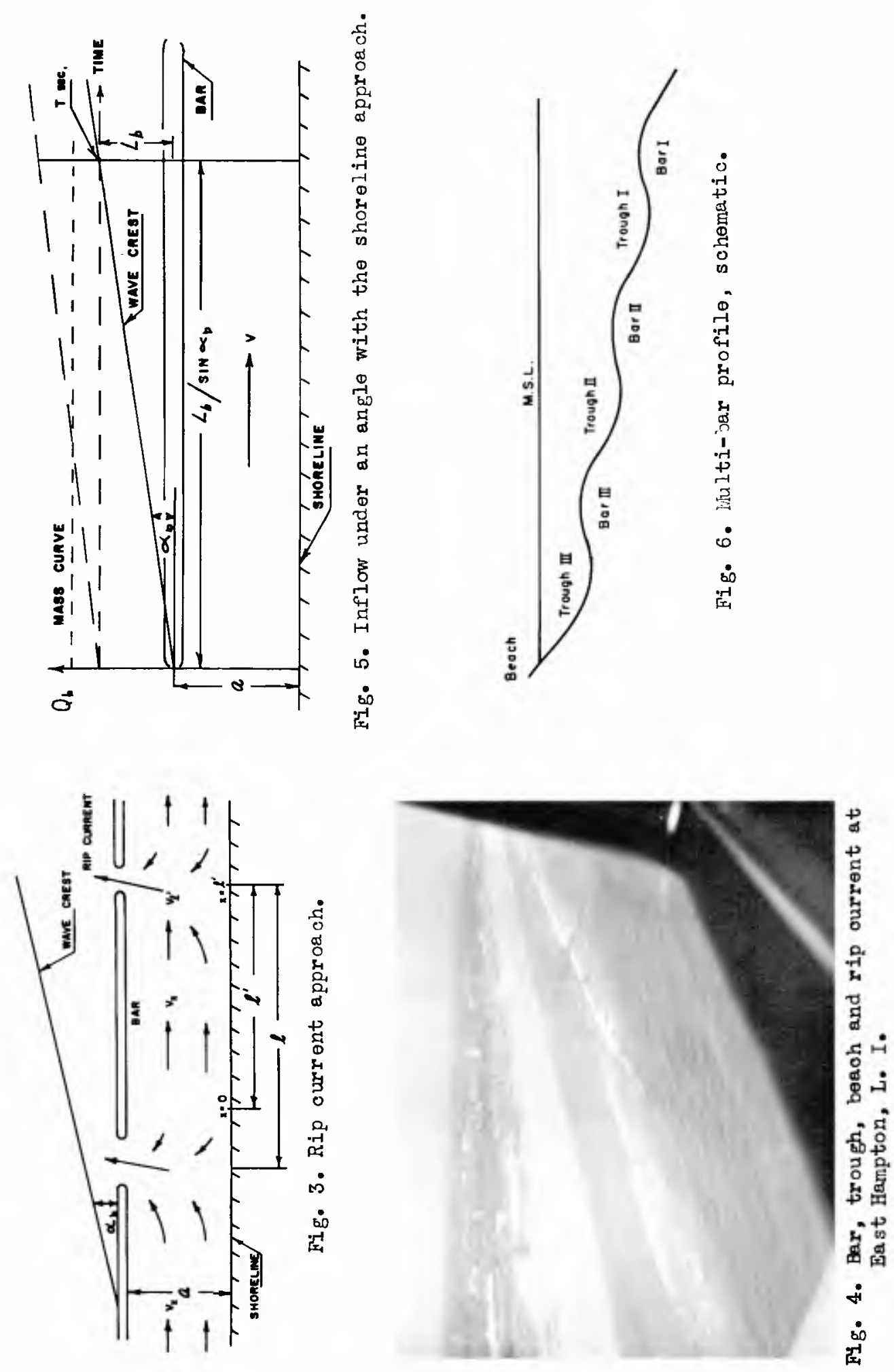


\section{COASTAL ENGINEERING}

With a 500-meter space between the rip current's average values of approximately $0.3 \mathrm{~kg} / \mathrm{m}^{2}$ for shear stresses and approximately $0.6 \mathrm{~m} / \mathrm{sec}$ for velocities are obtained considering normal storm waves of $T(1 / 3)=8 \mathrm{sec}$. and $C_{f}=35 \mathrm{~m} \frac{1}{2} / \mathrm{sec}$ (Table 1). When compared to the corresponding values for tidal inlets these figures are low. One explanation for this may be that the A value is counted higher than it actually is. Currents fill only part of the wave trough indicated in Figure 2. A reduction of $A$ to $2 / 3$ of its value or $700 \mathrm{~m}^{2}$ gives values for $\tau_{s}$ and $V$ which are close to the results from tidal inlets where $\tau_{s}$ for currents heavily loaded with sediments is approximately $0.50 \mathrm{~kg} / \mathrm{m}^{2}$ with velocities of about $0.9-1 \mathrm{~m} / \mathrm{sec}$. Another and perhaps more correct explanation is mentioned in section 5 dealing with longshore currents in a multi-bar profile. The relatively low value of $\tau_{s}$ may be caused by the waye action.

\section{APPROACH BASED ON INFLOW OF WATER UNDER AN ANGLE WITH THE SHORELINE}

Consider a wave approaching the shore (Figure 5). Its wave length when breaking is $L_{b}$, breaker angle $\alpha_{b}$ and content of water mass per unit length $Q_{B}$. The inflow of water over a length of shore of unit length is $Q_{B} \cos \alpha_{b}$ in $T$ sec. Water from a length of wave crest corresponding to one wave length $L_{b}$ passes in over a length of shore of $\mathrm{Lb} / \mathrm{sin} \alpha_{b}$. Total inflow of water in $T$ sec over $L_{b} / \sin \alpha_{b}$ length of shore is $Q_{B}$

$L_{b} \operatorname{cotg} \alpha_{b}$. A unit width of shore gets $\frac{Q_{B} \cos \alpha_{b}}{T}$ per sec. The inflow over a unit width takes place in $\frac{T \sin \alpha_{b}}{L b}$ seconds.

Assuming that the water table behind the breaking point is comparatively even and horizontal, the water level theoretically raises $\frac{Q B \cos \alpha_{b} \sin \alpha_{b}}{1 \cdot a \cdot L_{b}}$ where $a$ is distance from inside bar to the shoreline. One unit length downstream the water table is still undisturbed by the breaking wave, for which

reason the slope of the water surface $I=\frac{Q_{B} \cos \alpha_{b} \sin \alpha_{b}}{1 \cdot a \cdot L_{b}}=$ $\frac{Q_{B} \sin 2 \alpha_{b}}{2 a L_{b}}$. Using Chezy's formula one has: $V_{m}=C_{f} \sqrt{R I}$ where $R$ is hydraulic radius of trough. 


\section{LONGSHORE CURRENTS IN ONE AND MULTI-BAR PROFILES RELATION TO LITTORAL DRIFT}

It is here assumed that the water flows out again uniformly across the crest of the bar. This will normally not be the case because of the existence of rip currents but with rip currents spaced a considerable distance apart it will be true for a certain distance longshore. Close to the rips velocity may increase because of increase of slope caused by the discharge.

Table 3 has $V$-values computed on the basis of Figure 2 's average values of $A$ and the corresponding value of $a$ and with the same $A, T$, and $C_{f}$ values as determined in the preceding paragraph.

Table 3. Longshore Current Velocities Based on Inflow of Water under an Angle with the shoreline for Prototype Characteristics Corresponding to Figure 2.

\begin{tabular}{cccccc}
\hline $\begin{array}{c}\alpha_{b} \\
\text { degrees }\end{array}$ & $\begin{array}{c}\mathrm{L}_{\mathrm{b}} \\
\text { meters }\end{array}$ & $\begin{array}{c}\mathrm{T}(1 / 3) \\
\text { sec } \\
\text { ave }\end{array}$ & $\begin{array}{c}\mathrm{H}_{\mathrm{b}}(1 / 3) \\
\text { meters }\end{array}$ & $\begin{array}{c}\mathrm{Vm} \text { meter } / \mathrm{sec} \\
\left(\mathrm{C}_{f}=35 \mathrm{~m}^{\frac{1}{2}} / \mathrm{sec}\right)\end{array}$ & $\begin{array}{c}\mathrm{Vm} \text { meter } \\
\left(\mathrm{C}_{f}=45 \mathrm{~m}^{\frac{1}{2}} / \mathrm{sec}\right)\end{array}$ \\
\hline 25 & 55.0 & 8 & 5.5 & 1.20 & 1.55 \\
\hline 25 & 72.0 & 10 & & 1.12 & 1.45 \\
\hline
\end{tabular}

With $T(1 / 3)=8 \mathrm{sec}$ and $T(1 / 3)=10 \mathrm{sec}$ and $C_{f}=35 \mathrm{~m}^{\frac{1}{2}} / \mathrm{sec}$ these velocities are directly comparable to those found for tidal inlets. With $\mathrm{C}_{f}=45 \mathrm{~m}^{\frac{1}{2}} / \mathrm{sec}$ corresponding to the logarithmic formula they are somewhat high. This could be expected because of the idealized conditions. Moreoyer it should be remembered that Chezy's formula is valid for uniform flow, and a longshore wave current can hardly be classified as such.

\section{COMPARISON WITH PUTNAM, MUNK, AND TRAYLOR'S MOMENTUM APPROACH}

In order to make a comparison with this approach, current velocities were computed for the same profile and wave characteristics as used in earlier approaches. The velocity of the water particles at wave breaking is equal to the wave celerity $\mathrm{c}=\frac{\mathrm{L}_{\mathrm{b}}}{\mathrm{T}}$. Results are given in Table 4 , which shows very high velocities that are not in agreement with field experience. 


\section{COASTAL ENGINEERING}

Table 4. Longshore Current Velocities Based on the Momentum Approach by Putnam, Munk, and Traylor, (bar-profile Figure 2 characteristics).

\begin{tabular}{ccccc}
\hline $\begin{array}{c}\alpha_{b} \\
\text { degrees }\end{array}$ & $\begin{array}{c}\mathrm{L}_{\mathrm{b}} \\
\text { meters }\end{array}$ & $\begin{array}{c}\mathrm{T}(1 / 3) \\
\text { sec } \\
\text { ave }\end{array}$ & $\mathrm{H}_{\mathrm{b}}=\mathrm{H}_{(1 / 3)}=1.25 \mathrm{Dcr}$ & $\begin{array}{c}\mathrm{Vm} \\
\text { meters }\end{array}$ \\
\hline 25 & 55.0 & 8 & 5.5 & 2.6 \\
\hline 25 & 72.0 & 10 & 5.5 & 2.6 \\
\hline
\end{tabular}

In this respect it should be remembered that waves are regenerated behind the bar after breaking, by which process momentum is transferred as wave and not current momentum. This will cause current velocities to be high by 10 to 30 per cent if computed without a proper reduction for regeneration of waves (Mashima, 1958).

Furthermore the longshore current was computed for the part of the profile located inside the $4.4 \mathrm{~m}$ (equal to Dcr) depth contour in the profile (Figure 2) using $\mathrm{Hm}=\mathrm{Dcr}$ and integrating from $\mathrm{p}=0.5$ to $\mathrm{p}=\%$

Results are given in Table 5, and it may be seen that current velocities are even higher than in Table 4. The $k$ value according to Inman and Quinn (1952) is approximately 0.0007 , corresponding to a very high and unrealistic $C_{f}$ value (Table 1). Conditions on a sloping beach are neither comparable to trough nor tidal inlet conditions. Velocities of the order indicated in Table 5 may occur instantly but hardly averagely.

Table 5. Longshore Current Velocities Based on the Momentum Approach by Putnam, Munk, and Traylor (no-bar profile, Figure 2 slope characteristics).

\begin{tabular}{ccccc}
\hline $\begin{array}{c}\alpha_{b} \\
\text { degrees }\end{array}$ & $\begin{array}{c}\mathrm{L}_{\mathrm{b}} \\
\text { meters }\end{array}$ & $\begin{array}{c}\mathrm{T}(1 / 3) \\
\text { sec } \\
\text { ave }\end{array}$ & $\mathrm{H}_{\mathrm{b}}=\mathrm{Hm}=\mathrm{Dcr}$ & $\begin{array}{c}\mathrm{Vm} \\
\text { meters }\end{array}$ \\
\hline 25 & 55.0 & 8 & 4.4 & $>3.0$ \\
\hline 25 & 72.0 & 10 & 4.4 & $<3.0$ \\
\hline
\end{tabular}




\section{LONGSHORE CURRENTS IN ONE AND MULTI-BAR PROFILES RELATION TO LITTORAL DRIFT}

\section{LONGSHORE CURRENTS IN MULTI-BAR SYSTEM}

Reference is made to the schematic Figure 6 depicting a multi-bar profile.

When waves have passed over the outermost bar no. I they continue travelling across the trough between the bars until breaking takes place on bar no. II. The wave height which determines the depth over the crest of bar no. II is assumed to have the same ratio to this depth as valid for bar no. I or:

$$
\frac{\mathrm{H}(1 / 3 \mathrm{~b} 1)}{\mathrm{H}(1 / \mathrm{x} \mathrm{b} 2)}=\frac{\mathrm{D}(\mathrm{cr} 1)}{\mathrm{D}(\mathrm{cr} 2)}=\mathrm{k}(1.2)
$$

In the one-bar profile $\mathrm{H}(1 / 3 \mathrm{~b} 1)=1.25$ (Dcr1) and can be computed from known Dcr data. H(1/x b2) in the above equation is $\mathrm{H}(1 / 3 \mathrm{~b} 1) / \mathrm{k}(1.2)$ where $\mathrm{k}(1.2)$ is determined from known Dcr data. Using Longuet-Higgins distribution of wave heights and frequencies the probability (p) value corresponding to $\mathrm{H}(1 / 3 \mathrm{~b} 1) / \mathrm{k}(1.2)$ can be found.

The corresponding $\mathrm{Q}_{\mathrm{B} 2}$ 'value for the amount of inflow of water by breaking of waves the height of which lie between the boundaries mentioned above is:

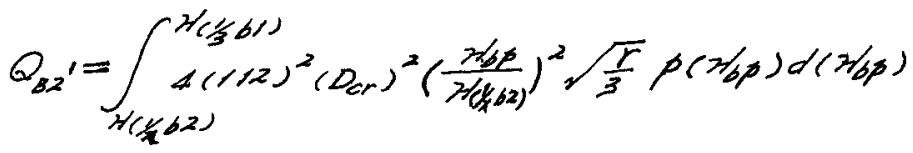

This quantity flows in during a period corresponding to the waves represented by the integration limits.

To this quantity has to be added the contribution by the waves which broke on bar no. I. A broken wave may not be regenerated as a single wave but as two or three waves with the result that the (apparent) wave period after wave breaking is smaller than the period before wave breaking. In the reasonings made below it is assumed that only one wave is regenerated. The height of this wave depends upon the loss of wave energy by the breaking process.

It is observed in the field that more waves break on bar no. II than on bar no. I and that more waves break on bar no. III than on bar no. II. The average height after first wave breaking therefore probably lies between $H(1 / 3 \mathrm{~b} 1)$ and $\mathrm{D}(\mathrm{cr} 2)$. 


\section{COASTAL ENGINEERING}

It is assumed that it is $D(c r 1)$ although there is no direct field experimental proof of this postulate. The $Q_{B}$ quantity derived from these waves is:

$$
\mathrm{Q}_{\mathrm{B} 2}{ }^{\prime \prime}=4[0.9 \mathrm{D}(\mathrm{cr} 1)]^{2} \cdot \sqrt{\frac{r}{3}} \cdot \mathrm{p}
$$

$(p=$ probability of occurrence)

This quantity of flow passes in during a period of time corresponding to $T(1 / 3)$ from the breaking on bar no. $I$. $T(1 / 3)$ is to be understood as the average value of periods in the spectrum from $\mathrm{T}_{1 / 3}$ actual period and up. One has:

Passing on to bar no. III the same approach may be used.

$$
\frac{H(1 / 3 b 2)}{H(1 / x b 3)}=\frac{D(c r 2)}{D(c r 3)} \text { which gives } H(1 / x \text { b3 })
$$

The inflow of water over bar no. III, $Q_{B 3}$ is composed of the same two quantities as mentioned above:

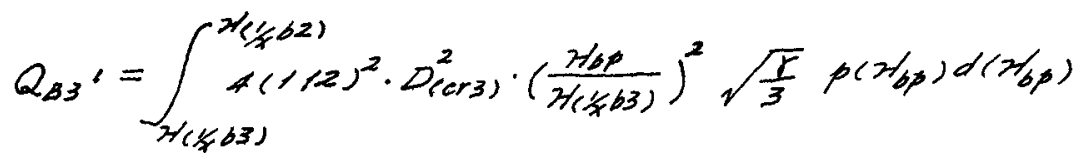

This water flows in during a period of time corresponding to an average value of the integration limits. To this must be added:

$$
\mathrm{Q}_{\mathrm{B} 3^{\prime}}=4[0.9 \cdot \mathrm{D}(\mathrm{cr} 2)]^{2} \cdot \sqrt{\frac{F}{3}} \cdot \mathrm{p}
$$

( $p=$ probability of occurrence)

This quantity of flow passes in during a period of time corresponding to the integration limits for the inflow from breaking waves over bar no. II.

For computation of the longshore current the slope approach should be used because the rip current approach assumes knowledge about the outflow of water through a multibar system and such knowledge will hardly ever be available $r=1$ as in preceding chapters of this article. 


\section{LONGSHORE CURRENTS IN ONE AND MULTI-BAR PROFILES RELATION TO LITTORAL DRIFT}

For the longshore current in trough no. I/II (between bars no. I and II) the $Q_{B}$-value to be used should be:

$$
Q_{B 1^{\prime}}-\left(Q_{B 2^{\prime}}+Q_{B 2}{ }^{\prime \prime}\right)
$$

with the corresponding $A$ and $\alpha_{b}$-values.

For the longshore current in trough no. II/III (between bars no. II and III) the $Q_{B}$-value to be used should be:

$$
\left(Q_{B 2}{ }^{\prime}+Q_{B} 2^{\prime \prime}\right)-\left(Q_{B}{ }^{\prime}+Q_{B}{ }^{\prime \prime}\right)
$$

with the corresponding $A$ and $\alpha_{b}$-values.

Examination of a multi-bar profile including four bars surveyed repeatedly at the old skaw at the northernmost tip of the Danish North Sea coast (Figure 7) has given the average values for Dcr listed in Table 6 below. Table 7 indicates average values of trough areas between the bars measured between verticals placed at the top of the crest of the respective bars.

Tab1e 6. Depth in Meters on Crest of Bar, Average of 5 Profiles Spaced Approximately 100 Meters Apät

\begin{tabular}{lcccc}
\hline Bar no. & I & II & III & IV \\
\hline Depth, m & 4.4 & 3.0 & 1.5 & 0.5 \\
\hline
\end{tabular}

Table 7. Average Area in Square Meters of Trough Between Bars of 5 Profiles Spaced Approximately 100 Meters Apart

\begin{tabular}{lccc}
\hline Trough no. & $\mathrm{I} / \mathrm{II}$ & $\mathrm{II} / \mathrm{III}$ & $\mathrm{III} / \mathrm{IV}$ \\
\hline Area, $\mathrm{m}^{2}$ & $15,8 \cdot 10^{2}$ & $8.2 \cdot 10^{2}$ & $2.6 \cdot 10^{2}$ \\
\hline
\end{tabular}

With respect to the interrelation between depth on bar and area of trough in the multi-bar profile it should be remembered that the overall profile as we find it by surveys (in the summer time) does not necessarily correspond to one particular storm which created wave breaking on all bars. Most storms will hardly interfere with the outermost bar. Comparing conditions in the sumer and winter seasons it is obvious that the nearshore bars will be most affected by the 


\section{COASTAL ENGINEERING}

wave activity in the summer season while the offshore bars are mainly related to winter storms. The bars may migrate a little closer to shore in the summer season and this may change the elevation of the crest slightly and also the configuration of the trough. Based on experience with onebar as well as multi-bar profiles changes may not be very important (see Figure 2) and similar experience is available for the situation depicted in Figure 7 .

Assuming a storm causing wave action with an average period of $8 \mathrm{sec}$ by waves from $\mathrm{T}_{1 / 3}$ and up and heights $\geq \mathrm{H}_{1 / 3}$ actual height at breaking on bar no. I, the $Q_{B}$-values over four bars are computed as listed in Table 8 .

Table 8. QB-Values in Cubic Meters Per Meter of Wave Crest for Multi-Bar System.

\begin{tabular}{|c|c|c|c|c|c|}
\hline Bar no. & & Bar no. II & Bar no. & III & Bar no. IV \\
\hline $\mathrm{Q}_{\mathrm{B} 1}{ }^{\prime}$ & $\mathrm{Q}_{\mathrm{B} 1}{ }^{\prime \prime}$ & $\mathrm{Q}_{\mathrm{B} 2}{ }^{\prime}$ & $\mathrm{Q}_{\mathrm{B} 3}{ }^{\prime}$ & $\mathrm{Q}_{\mathrm{B} 3}{ }^{\prime \prime}$ & $\mathrm{Q}_{\mathrm{B} 4}{ }^{\prime}$ \\
\hline 12.1 & 0 & 5.14 & 0.78 & 3.12 & 0.09 \\
\hline $\begin{array}{l}\sum Q_{B 1}= \\
m^{3} / m \text { of }\end{array}$ & $\begin{array}{l}12.1 \\
\text { crest }\end{array}$ & $\begin{array}{l}\Sigma Q_{B 2}=8.6 \\
\mathrm{~m}^{3} / \mathrm{m} \text { of crest }\end{array}$ & $\begin{array}{l}\Sigma Q_{\mathrm{B} 3} \\
\mathrm{~m}^{3} / \mathrm{m} \text { o }\end{array}$ & $\begin{array}{l}=3.9 \\
f \text { crest }\end{array}$ & $\begin{array}{l}\Sigma Q_{B_{4}}=1.3 \\
\mathrm{~m}^{3} / \mathrm{m} \text { of crest }\end{array}$ \\
\hline
\end{tabular}

The corresponding $\mathrm{T}$-values are listed in Table 9.

Table 9. T-Values in Seconds Corresponding to Table 8's $Q_{B}-$ Values

\begin{tabular}{|c|c|c|c|c|c|c|c|c|}
\hline Bar no. I & & Bar no & - II & & Bar no. & III & Bar no & - IV \\
\hline $\mathrm{Q}_{\mathrm{B} 1}{ }^{\prime}$ & & $\mathrm{Q}_{\mathrm{B} 2}{ }^{\prime}$ & $\mathrm{Q}_{\mathrm{B} 2^{\prime \prime}}$ & & $\mathrm{Q}_{\mathrm{B} 3^{\prime}}{ }^{\prime}$ & $Q_{B 3}{ }^{\prime \prime}$ & $\mathrm{Q}_{\mathrm{B} 4^{\prime}}$ & $\mathrm{Q}_{\mathrm{B} 4}{ }^{\prime \prime}$ \\
\hline $\begin{array}{c}T=8 \\
\text { sec }\end{array}$ & $\mathrm{T}$ & $\begin{array}{l}=6.6 \\
\mathrm{sec}\end{array}$ & $\begin{array}{c}T=8 \\
\text { sec }\end{array}$ & $\mathbf{T}$ & $\begin{array}{l}=5.7 \\
\mathrm{sec}\end{array}$ & $\begin{array}{c}T=6.6 \\
\sec \end{array}$ & $\begin{array}{c}T=4.9 \\
\text { sec }\end{array}$ & $\begin{array}{c}T=5.7 \\
\text { sec }\end{array}$ \\
\hline
\end{tabular}

With $\alpha_{b 1}=25^{\circ}, \alpha_{b 2}=21^{\circ}$ and $\alpha_{b 3}=15^{\circ}$ the current velocities 1 isted in Table 10 are obtained. 
LONGSHORE CURRENTS IN ONE AND MULTI-BAR PROFILES RELATION TO LITTORAL DRIFT

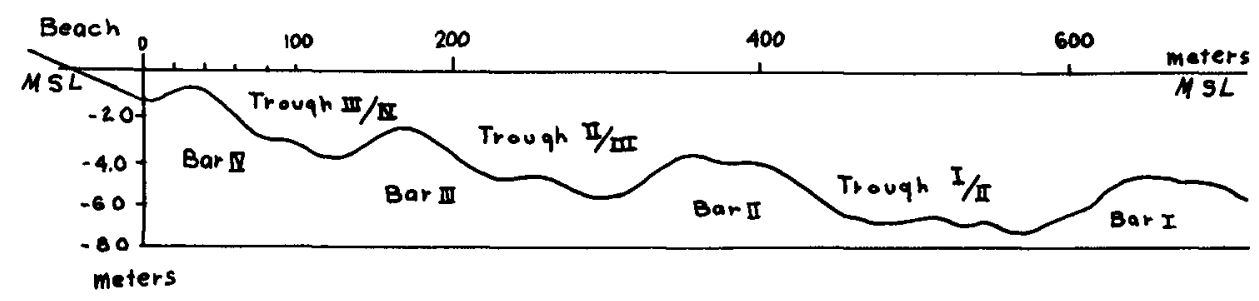

Fig. 7. Wulti-bar profile at The Old Skaw, Denmark.

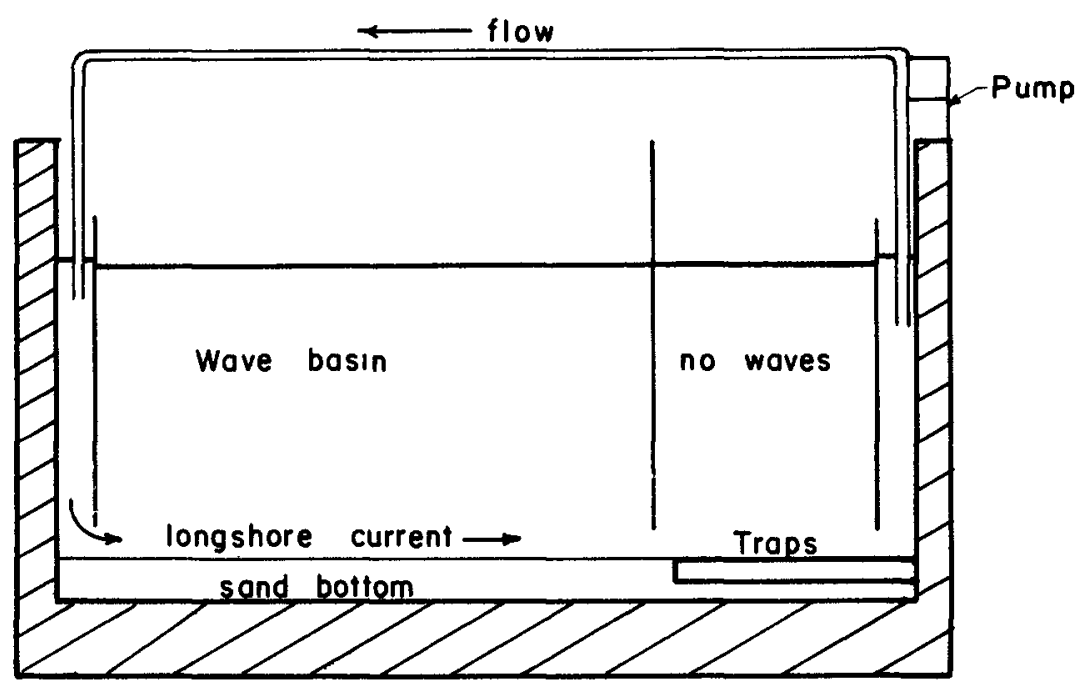

Fig. 8. Wave tank experiment on bed transport. 


\section{COASTAL ENGINEERING}

Table 10. Current Velocities in Meters Per Sec. in Troughs nos. I/II, II/III and III/IV $\mathrm{C}_{\mathrm{f}}=35$ or $45 \mathrm{~m}^{\frac{1}{2}} \mathrm{sec}^{-1}$

\begin{tabular}{cccc}
\hline $\begin{array}{c}\mathrm{C}_{f} \\
\mathrm{~m}^{\frac{1}{2}} / \mathrm{sec}\end{array}$ & $\begin{array}{c}\text { Trough no. I/II } \\
Q=3.48 \mathrm{~m} / \mathrm{m}\end{array}$ & $\begin{array}{c}\text { Trough no. II } / \text { III } \\
Q=4.72 \mathrm{~m}^{\frac{1}{3}} / \mathrm{m}\end{array}$ & $\begin{array}{c}\text { Trough no. III/IV } \\
Q=3.90 \mathrm{~m}^{3} / \mathrm{m}\end{array}$ \\
\hline 35 & $0.4 \mathrm{~m} / \mathrm{sec}$ & $0.7 \mathrm{~m} / \mathrm{sec}$ & $0.5 \mathrm{~m} / \mathrm{sec}$ \\
\hline 45 & $0.5 \mathrm{~m} / \mathrm{sec}$ & $0.9 \mathrm{~m} / \mathrm{sec}$ & $0.7 \mathrm{~m} / \mathrm{sec}$ \\
\hline
\end{tabular}

These velocities seem to be realistic and are in good agreement with velocities derived from tidal hydraulics computations for inlets with alluvial bottom (Bruun and Gerritsen, 1960 , referring to its Table $5^{\prime} \mathrm{s}(\mathrm{p} .67)$ figures for $\tau_{\mathrm{s}}$ under moderate to heavy wave action which corresponds to velocities of 0.5 to $0.8 \mathrm{~m} / \mathrm{sec}$ as we have found here).

It is natural that currents in the multi-bar profile are slower than in the one-bar profile (Table 3) where the breaking wave delivers all of its water in one breaking while in a multi-bar profile water from each trough is passed on by breaking into the next following trough.

With respect to transfer of momentum from one trough to the other such transfer, needless to say, does take place but it is not accounted for in the above considerations. It should not be forgotten, however, that the transfer of water takes place from an area just outside the bar where longshore trough velocities are smallest. A certain momentum should still be added but at the same time another momentum derived from the loss of a similar quantity of water by outflow from the trough inside the bar in question to the trough outside the bar in question reduces the momentum of water flow inside the bar. If velocities are equal on both sides of the bar the final result may be close to zero. During storm conditions which are determining for pertinent dimensions of bars and troughs, velocities may not differ too much but local increases and decreases may occur in the area where water flows out more concentrated as e.g. In rip currents instead of in an equally distributed "undertow". Currents will then be accelerated on the updrift side of the rip and decelerated or even reversed on the downdrift side. Such situation is most predominant when waves propagate in a direction which is not far from being perpendicular to the shoreline. With waves coming in under a great angle of incidence (as they do at the 01d skaw) rips still come into existence but they may be turned downstream. 


\section{LONGSHORE CURRENTS IN ONE AND MULTI-BAR PROFILES RELATION TO LITTORAL DRIFT}

\section{DISCUSSION}

Comparing the results indicated in Tables 2 to 5 , it may be seen that the continuity approach whether in the "rip current" or the "inflow under an angle" or "slope" approach gives realistic values for velocities and/or shear stresses for the above mentioned one-bar profile depicted in Figure 2 . The momentum approach seems to give values which are too high for this profile and undoubtedly also too high for the longshore current inside the final breaking point on the beach, although such velocities may occur instantly in a narrow belt close to the breaker line at steep beaches.

It is encouraging to see that the continuity approach in the inflow under an angle version seems to be very suitable for use in a multi-bar profile as demonstrated by the velocities in Table 10. As in case of the one-bar profile, velocities are realistic and compare well with velocities found for tidal inlets in alluvial material although the velocity distribution and pattern must differ somewhat in the two cases.

Generally it may be said that the continuity approach, whether in the "rip current" or in the "longshore slope" approach, has an advantage over the momentum approach, because when used in a one or multi-bar bottom profile no reduction of momentum caused by the formation of waves inside the breaking point has to be considered. After breaking on the bar waves will travel shoreward and finally break on the beach slope, giving rise to up and down rush and a corresponding longshore zig-zag current superimposed on the current derived from earlier breakings. The momentum available inside the first breaking point is the difference between the momentum in the breaking wave and the momentum used for the formation of waves behind the bar after breaking. By not taking the formation of new waves into consideration the current based on the momentum approach will be too high, as mentioned above. The momentum approach for bar profiles is also less applicable because one is not only faced with the normal problem of selecting the waves which actually break over the bar, but also with the problem of a proper momentum reduction because of regeneration of waves behind the bar. The continuity approach also includes the problem of selection of waves which break, but the mass transport in the relatively smaller waves in the spectrum is less important. Reflection of wave energy occurs in both cases but is of minor importance. 


\section{COASTAL ENGINEERING}

The continuity approach compared to the momentum approach has one very definite advantage because it does not include an uncertain determination of the velocity of the water particles in the breaking wave. It seems, therefore, to be a reasonable conclusion that the continuity approach has several advantages in one or multi-bar profiles. On the other hand the longshore current occurring in connection with the final wave breaking and up and down rush on the beach itself may be computed by the momentum approach which was developed mainly for this particular case. The continuity approach ignores the momentum which does occur during wave breaking, but it is a fact that not too much is felt of that momentum at a certain distance inside the bar(s). Most of it disappears because of high turbulence and therefore rapid decrease in velocities just inside the bar.

On the other hand it is clear that this longshore current problem is of such a nature that it discourages a pure "deskapproach." It is necessary to go out in the field and make observations in order to furnish the data necessary for a reliable evaluation and computation. It may therefore be said that the continuity approach, particularly when based on a rip current distribution, requires prior information on the result one is seeking, but in this respect it should be remembered that after a certain number of observations a file of data may be built up allowing a reduction of field observations and permitting a higher degree of pre-determination by straight computation.

The field information needed is, first of all, detailed knowledge about the bottom topography and its fluctuations. Next, knowledge about the wave spectrum and the approach angle of wave crests is needed. An evaluation of the bottom friction must be based on experience, inasmuch as a pure estimation of relative roughness using results from fluid mechanics technology would not furnish us with any useful figure. Laboratory experiments of the nature depicted in Figure 8 and mentioned in the following section may be able to furnish valuable information useful in the prototype.

\section{LITTORAL DRIFT AND LONGSHORE CURRENTS}

The longshore littoral transport of material is caused by a combination of shear stresses by wave action which "breaks loose" the material and shear stresses by longshore currents which transport the material parallel to shore. 


\section{LONGSHORE CURRENTS IN ONE AND MULTI-BAR PROFILES RELATION TO LITTORAL DRIFT}

The main direct contribution to the material movements by the waves is almost perpendicular to the shoreline and the maximum velocities of the oscillating water movement will normally exceed the longshore current velocities considerably. But the longshore material movement is still caused by the longshore current. If it were not there no longshore movement would take place.

In a uniform flow, shear stress between flow and bottom $\tau=\rho V_{x}{ }^{2}$. The work transferred to the bottom is, therefore, proportional to $\tau \cdot f\left(V_{x}\right) \sim V_{x}{ }^{3} \sim \tau^{3 / 2}$ (Bagnold 1956). This work is used for bed-load movement and for stirring up material by lift forces which are also proportional to $\boldsymbol{T}$. The actual magnitude of bed-drift may depend upon $\left(T^{3 / 2}\right)^{n}$ where $n$ varies according to different authors from 1 to 2 with some modifications in power relationship mainly due to the introduction of $\tau_{c}$ which is the shear stress by which movement of bed material starts.

Considering the situation on sea shores and combining the material moving forces perpendicular to as well as parallel to shores it may be assumed that the magnitude of drift per unit area of the bottom is a function of $W_{*}$ (in oscillating wave motion) times a function of $V_{*}$ (in the longshore current) or $f\left(W_{*}\right) \cdot f\left(V_{*}\right)$.

Certain experiments of recent date seem to reveal that the erosion of a sand bottom in turbulent flow is proportional to the square of the standard deviation of velocity fluctuations $\sigma^{2}$ which in turn is proportional to $V_{\star}^{2} \sim \tau$. The work to be done to move the material perpendicular to shore is $\tau_{\mathrm{W} *} \sim \mathrm{W}_{*}{ }^{3} \sim \tau^{3 / 2}$.

Bretting's (1960) expression for bed-load transport $\mathrm{q}_{\mathrm{s}}=0.0617\left(\frac{\tau}{\tau_{\mathrm{c}}}-1\right)^{2} \mathrm{~d}_{\mathrm{m}} 3 / 2\left(\frac{\mathrm{m} 3}{\mathrm{~m} \text { sec }}\right)$ includes the factor $\left(\tau / \tau_{c}-1\right)^{2}$ which for high values of $\tau / \tau_{c} \sim \tau^{2}$. DuBoys' and Shields' bed load formulas of earlier date have similar relationships.

With waves and longshore currents combined the total water current along the bottom includes as described above an oscillating wave part which is almost perpendicular to shore and an alongshore component by the longshore current. The first component will usually have the main responsibility for breaking loose the material from the bottom (by $\tau$ trans- 


\section{COASTAL ENGINEERING}

versal-shear stresses) while the longshore current carries the material sideways (by $T$ longshore-shear stresses). There seems, therefore, to be some reason to make the littoral transport per unit area proportional to $\tau_{\text {trans }} x$ Tlongs rather than $\left(\tau_{\text {trans }}\right)^{2}$ or $\left(\tau_{\text {longs }}\right)^{2}$. One has $\tau_{\text {trans }} \sim \frac{\mathrm{H}^{2}}{\mathrm{~T}^{2}}$ for stokes finite height waves and Tlongs $\sim \frac{\mathrm{H}^{2}}{\mathrm{~T}^{2}} \sin 2 \alpha_{\mathrm{b}}$ using the longshore slope theory described in section 4. Assuming that hydraulic radius of the longshore trough is proportional to the breadth "a" of the bottom affected by wave action one has $\mathrm{a} \sim \mathrm{H}$. This gives $\tau_{\text {trans }} \cdot \tau_{\text {longs }} \cdot \mathrm{H} \sim \frac{\mathrm{H} 5}{\mathrm{~T}^{4}} \sin 2 \alpha_{\mathrm{b}} \sim$ $\mathrm{H}^{2} \mathrm{~L} \sin 2 \alpha_{\mathrm{b}}$ in as much as $\mathrm{H} \sim \mathrm{T}{ }_{\mathrm{L}} \mathrm{L}$ for storm waves. Similar reasonings may be made with Solitary and Cnoidal waves where the horizontal orbital velocity is $\sim \sqrt{\mathrm{g}(\mathrm{H}+\mathrm{d})}$. That the expression above is similar to the so-called "Los Angeles formula" according to which the littoral drift is proportional to the longshore wave energy should only be understood as "a possible indication of similarity." It is in this respect interesting to note that the results of laboratory experiments by Krumbein as explained by Bruun (1951) may be arranged on a second order parabola, or: $\mathrm{QT} / \mathrm{LO}^{2} \mathrm{HO}_{\mathrm{O}}=\mathrm{k}\left(\frac{\mathrm{HO}}{\mathrm{LO}_{\mathrm{O}}}\right)^{2}$ which gives $Q=k E_{f} \cdot \frac{H_{O}}{L_{O}}$ valid up to $\frac{H_{O}}{L_{O}}=0.035 . \quad(Q=$ quantity of $\mathrm{drift})$.

The "Los Angeles formula" might to some extent have been confirmed by field experience. See caldwell (1956) and Lillevang (1960). It points in the direction of maximum drift for breaker angles of $30^{\circ}-40^{\circ}$ which in turn corresponds to $a \alpha_{0}$ of $45^{\circ}$ to $70^{\circ}$, all depending upon wave and depth characteristics.

Laboratory experiments showed maximum at $30^{\circ}$ to $40^{\circ}$ (see Johnson, 1951, 1952, and Savage, 1962), but this result should not be transferred uncritically to field conditions. Larras (1957) lists, with reference to Sauvage and Vincent, $53^{\circ}$ (1954) based on laboratory experiments, Zenkovitch found $35^{\circ}-40^{\circ}$ on shingle beaches (1962) and Bruun (1954) approximately $50^{\circ}-55^{\circ}$ from field experiments of coastal morphology nature on prototype enminiature sand beaches. It is not likely that any "maximum angle" exists. It must vary with wave, bottom and bottom material characteristics.

Based on data from Florida (South Lake Worth Inlet) and Anaheim (California) Caldwell (1956) found the relationship: 


\section{LONGSHORE CURRENTS IN ONE AND MULTI-BAR PROFILES RELATION TO LITTORAL DRIFT}

$$
M=210 \mathrm{E}_{\mathrm{f}} 0.8
$$

where $M$ is the alongshore drift in cu. $y d$. per day and $E_{f}$ is alongshore energy in millions of $\mathrm{ft}-1 \mathrm{bs}$ per day per foot of beach. This formula only deviates from the "Los Angeles formula" by its power for $\mathrm{B}_{\mathrm{f}}$ which is 0.8 instead of 1.0 . It is interesting to note this reduced power relationship which may be interpreted in the way that waves with high energy effect as e.g. storm waves are not utilized for littoral transport to the same extent as waves with less effect, a phenomena which may be explained by the loss of energy by plunging wave breaking including formation of heat and foam. Reference is made to the above mentioned experiments by Krumbein which also indicate that with high $\mathrm{H}_{\mathrm{O}} / \mathrm{L}_{\mathrm{O}}$ ratios wave energy is not as effective for littoral transport as with waves with lower steepness ratios.

Considerations of such nature are, needless to say, of a "superficial" nature but they may give a preliminary idea of the "possible importance" of some of the pertinent factors involved.

Going back to the more theoretical aspects of the problem the situation today is that the "breaking loose" forces are not well known and the longshore currents under a variety of boundary conditions are not known either. In order to obtain any rational results both must be investigated carefully, first separately and then combined.

Inasmuch as we still do not have a full understanding on bed-load transport phenomena in unidirectional flow there may still be a long road left before we obtain a more thorough understanding on the details of the movement under oscillating water movement. It would be a great step forward if some of the laws governing the migration of material under the influence of oscillating water motion could be revealed without going down to the very details. The movement of sand on a plane bottom has been investigated by a few authors as e.g. Ippen and Verma (1953) and Eagleson et al (1961), but so far few results have been obtained to correlate this movement with the actual water motion referring to the boundary layer just above the bottom where the irregular fluctuation of velocities mainly takes place for which reason 1 ift and shear forces necessary for material transport are produced. Hydraulic tests on the bottom roughness and friction problem (disclosing material transport) with varying depth and wave characteristics 


\section{COASTAL ENGINEERING}

may give some valuable information of primary interest for later detailed research on actual friction and transport characteristics including travel velocity, thickness of sheet layer and quantity of sand movement.

By the establishment of a longshore current of well known characteristics in a basin under wave action (see the schematic Figure 8) knowledge about the drift under conditions which have a great similarity to natural conditions may be obtained. A circulation system for water as well as sand is needed to imitate nature as closely as possible. Primary two-dimensional experiments on the roughness factors alone should be made. It would be a further advantage if introductorily tests could be made with a fixed bottom allowing observation of the bottom turbulence independent of disturbances by jumping sand grains from the bottom which may make independent recording of water turbulence very difficult.

In the field, research should probably concentrate on separate evaluation of two important problems, namely:

(1) An evaluation of the concentration of material in movement in suspension as well as in the bed-load sheet layer under various conditions of wave action at various depths and with various material. The individual parts of the bottom cross-section including the bar, the trough and the uprush zone should be investigated separately.

(2) An evaluation of the longshore current in the same sections of the profile at various depths and with various wave (and tide) characteristics.

Re. (1) With respect to evaluation of the quantity of material available for longshore drift as suspended-load and as bed-load modern tracing technique may be very helpful. Samples may be secured to give a complete picture of the concentration of material in the entire profile under known wave conditions to be described by a wave height and period spectrum and/or by a power spectrum.

The thickness of the moving sheet layer may be determined in the field by luminescent or other tracers allowing an estimation of quantity of drift in a certain area as function of time. The results should be compared with laboratory experiments as mentioned above. Such tests are at this time (1962) in progress at the Coastal Engineering Laboratory of the University of Florida. 


\section{LONGSHORE CURRENTS IN ONE AND MULTI-BAR PROFILES RELATION TO LITTORAL DRIFT}

Re. (2) Various ingredients are included in the longshore currents and they all make their contribution to the longshore drift. It will, therefore, be necessary to know these currents under a variety of circumstances also including conditions with no wave but possibly tide action. This will require a very detailed and comprehensive current measurement program.

The difficulty in determination of longshore current characteristics lies in the confused current pattern and the corresponding recording difficulties. In case the water is not greatly loaded with material recording of the current pattern may be made using dyes, but because of diffusion dyes will usually only be able to give an idea about the order of magnitude of the velocity. For recording of actual velocities staffs with vanes at different depths, jelly bottles and rugged current meters operated from fixed installations as e.g. piers are needed. Corresponding recording of the travel velocities of tracer grains may make it possible to interrelate observed longshore current velocities with the velocities of the migrating sand grains and thereby allow an estimation of drift quantities based on a combination of wave and longshore current velocity data. Even though a detailed understanding may not be secured, thereby much important and useful information may be obtained.

\section{SUMMARY AND CONCLUSION}

(1) This paper gives information on the preliminary results on longshore current theories based on a continuity approach.

(2) The earlier proposed momentum approach for computation of longshore currents (Putnam, Munk, and Traylor, 1949) may be valid under simplified conditions of bottom topography, but it seems to be less applicable for more involved conditions of coastal morphological and hydraulic nature as e.g. occurring at bar profiles, because knowledge is assumed about mass transport as well as water particle velocities involved in a wave breaking.

(3) The continuity approach is related to prototype conditions in a more simple way. Momentum inflow is omitted because it does not seem to be of much importance with a well developed bar profile. The continuity approach is to be preferred for use in one and multi-bar profiles. 


\section{COASTAL ENGINEERING}

(4) For computation of longshore currents, occurring in troughs between bars, detailed knowledge about the wave spectrum and its development or time history from deep water to the breaking point (s) is needed. Future research should, therefore include detailed studies of wave mechanics nature in the field.

A very comprehensive research program on transformation of waves from deep water to the shore is being undertaken by the Dutch "Deltadienst," using several towers loaded with instruments and placed on a line perpendicular to shore on the North Sea coast.

(5) Laboratory and field experiments seem to have furnished some information on the relationships between littoral drift characteristics and wave characteristics with special reference to longshore wave energy but not much understanding of the basic principles involved in the transport.

Further progress may be obtained by:

a Basic laboratory research including investigations of the nature of bed-load transport related to flow, material and bottom friction characteristics. An approach based on shear stress analysis to be extended from uniform flow into oscillating flow conditions seems preferable. It requires knowledge on friction characteristics and velocity distribution.

b. Laboratory and field research of basic nature concentrating on evaluations of macroscopic problems as the characteristics of the migrating sheet bed-load layer and its relations to wave and current characteristics, the characteristics of the suspended-load motion, its distribution in the profile and relation to wave and current characteristics and the magnitude of the material migrating along the shore in sand humps and waves.

c. New1y developed tracing techniques which may prove of great value in securing reliable data from the field, particularly data on transport rate in short periods of time with well known wave and current data. Such field experiments are in progress at the Coastal Engineering Laboratory of the University of Florida.

d. Based on the knowledge obtained it may be possible to calibrate future models with movable beds on basic principles for material transport rather than on "time history." 


\section{LONGSHORE CURRENTS IN ONE AND MULTI-BAR PROFILES RELATION TO LITTORAL DRIFT}

\section{REFERENCES}

Bagnold, R. A., 1956, The flow of cohesionless grains in fluids: Royal Soc. London Trans., Sec. A., V. 249, p. 235-297.

Beach Erosion Board, Corps of Engineers, An experimental study of submarine bars, Technical Report No. 3, 1948, 40 pages.

Bowden, A. J., 1962, The investigation of the transport of sediment in uniform systems by observations of tracer distribution, Hydraulic Research Station, Dept. of Scientific and Industrial Research, Report no. IN 25, (England).

Bretschneider, C. L., A theory for waves of finite height, Coastal Engineering No. 7, Proceedings of the 7th International Conference on Coastal Engineering in The Hague, Netherlands, Council on Wave Research, Berkeley, 1961, pp. 146-183.

Bretting, A. E., 1960, Hydraulik: Copenhagen Danish Technical Press, $518 \mathrm{p}$.

Bruun, P., Coast Stability, Danish Technical Press, 1954, 400 pages.

Bruun, P., and Gerritsen, F., "Stability of Coastal Inlets", North Holland Pub1ishing Company, Amsterdam, 1960, 123 pp.

Caldwe11, J. M., 1956, Wave Action and sand movement near Anahein Bay, California Tech. Memo. No. 68, Beach Erosion Bd, Corps of Engineers, U. S. Dept. of the Army.

Chang, Y. L., 1939, Laboratory investigation of flume traction and transportation, Trans. Am. Soc. of Civil Engineers, Vo1. 104, pp. 1246-1289.

Eagleson, P. S., Glenne, B., and Dracup, J. A., 1961, Equilibrium characteristics of sand beaches in the offshore zone, M.I.T., Hydrodynamics Laboratory, Technical Report, No. 41.

Fuchs, A., On the theory of short-crested oscillatory waves, Inst. of Eng. Research, Univ. of Calif., Berkeley, Series No. 3, Issue No. $326,1951,10$ pages.

Hartnack, W., Die Küste Hinterpommerns, Greifswald 1926.

Inman, D. L., and Nasu, N., Orbital velocity associated with wave action near the breaker zone, Corps of Engineers, Beach Erosion Board, Tech. Memo. No. 79, 1956, 43 pages. 
Inman, D. L., and Quinn, W. H., Currents in the Surf Zone, Proceedings of the 2nd Conference on Coastal Bngineering, Houston, Council on Wave Research, Univ. of Calif., Berkeley, 1952, pp. 24-36.

Ippen, A. T., and Kulin, G., Shoaling and breaking characteristics of the solitary wave, Massachusetts Institute of Technology, Hydrodynamics Laboratory, Technical Report No. 15, 1955, 56 pages.

Ippen, A. T., and Verma, R. P., 1953, The motion of discrete particles along the bed of a turbulent stream: Minn. Internat. Hydraulic Convention (Minneapolis) Proc., p. 7-20.

Iversen, H. W., Discussion of results from studies of wave transformation in shoaling water, including breaking, Inst. of Eng. Research, Univ. of Calif., Berkeley, Series No. 3, Issue No. 331, 1952, 16 pages.

Johnson, J. W., and Shay, E. A., 1951, Model studies on the movement of sand transported by wave action along a straight beach, Inst. of Engineering Research, University of California, Berkeley, Issue 7, Series 14, (unpublished).

Johnson, J. W., 1952, Sand transport by littoral currents, Proc. Fifth Hydraulic Converence, State University of Iowa, Studies of Engineering, Bulletin 34.

Keulegan, G. H., and Patterson, G. W., Mathematical theory of irrational translation waves, U. S. Dept. of Commerce, National Bureau of Standards, Vo1. 24, 1940, 100 pages.

Keulegan, G. H., Wave Motion, Engineering Hydraulics, Proc. Fourth Hydraulic Conf., ch. 11, pp. 711-68. Bd. by Hunter Rouse, Wiley, New York, 1950.

Rressner, B., Modellversuche über die Wirkungen der Brandungswellen und des Küstenstromes auf einen sandigen Meeresstrand und die zweckmässige Anlage von Strandbuhnen, Der Technischen Hochschule der Freien Stadt Danzig, 1928, 16 pages.

Laitone, E. V., Higher approximation to non-linear water waves and the limiting heights of Cnoida1, Solitary and Stokes' Waves, Hydraulic Engineering Laboratory, Wave Research Projects, Tech. Rept. 89-6, 1961, (Berkeley).

Larras, J., Plages et Cotes du Sable, Collection Du Laboratoire National D'Hydraulique, Eyrolles, Paris, 1957, 117 pages. 


\section{LONGSHORE CURRENTS IN ONE AND MULTI-BAR PROFILES RELATION TO LITTORAL DRIFT}

Le Méhauté, B., A theoretical study of waves breaking at an angle with a shore, Civil Engineering Department, Queen's University at Kingston, Ontario, Report No. 10, 1960, 8 pages.

Lillevang, 0. J., 1960, Mean direction of waves and of wave energy, Proc. Jour. Waterways and Harbors Division, V. 86, No. WW1, pp. 123-143.

Longuet-Higgins, M. S., On the statistical distribution of the heights of sea waves, Journal Marine Research, Vo1. 11, No. 13, Dec. 1952, pp. 245-266.

Mashima, Y., Study of the Typhoen Characteristics in Respect to Wave Development and the Distribution of Longshore Current, Coastal Engineering in Japan, Vo1. 1, 1958, pp. 1-20.

Munk, W. H., The Solitary wave theory and its application to surf problems, Annals of the New York Academy of Sciences, Vo1. 51, Art. 3, pp. 376-424, 1949.

Putnam, J. A., Munk, W. H., and Traylor, M. A., The prediction of longshore currents, Trans. Amer. Geophys. Un. Vo1. 30, pp. 337-345, 1949 .

Sauvage, M. G., and Vincent, M. G., 1954, Transport 1ittoral formation de fleches et de tombolos, Proc. Fifth Conference on Coastal Engineering, Grenoble, France, (Council on Wave Research, Berkeley).

Savage, R. P., 1962, Laboratory determination of littoral transport rates, Am. Soc. of Civil Engineers, Proc. Jour. Waterways and Harbors Division, V. 88, No. WW2, pp. 69-92.

Wiege1, R. L., A presentation of cnoidal wave theory for practical application, Journal of Fluid Mechanics, Vo1. 7, part 2, pp. 273286,1960 .

Wiege1, R. L., Wind Waves and Swe11, Coastal Engineering No. 7, Proceedings of the 7th Conference on Coastal Engineering, Den Haag, Holland. Council on Wave Research, Univ. of Calif., Berkeley, 1961, pp. 1-40. 